\title{
Diagnostic significance of CK19, galectin-3, CD56, TPO and Ki67 expression and BRAF mutation in papillary thyroid carcinoma
}

\author{
LIHUA HUANG $^{1 *}$, XUMING WANG ${ }^{2,3 *}$, XUAN HUANG ${ }^{2,3^{*}}$, HUAWEI GUI $^{1}$, \\ YAN LI $^{2,3}$, QIONGXIA CHEN ${ }^{2,3}$, DONGLING LIU ${ }^{1}$ and LIJIANG LIU ${ }^{2,3}$ \\ ${ }^{1}$ Department of Pathology, Wuhan Puai Hospital, Wuhan, Hubei 430030; ${ }^{2}$ Department of Histopathology, \\ Jiangda Pathology Institute, and ${ }^{3}$ Department of Pathology and Pathophysiology, School of Medicine, \\ Jianghan University, Wuhan, Hubei 430056, P.R. China
}

Received November 1, 2016; Accepted September 22, 2017

DOI: $10.3892 / \mathrm{ol} .2018 .7873$

\begin{abstract}
The aim of the present study was to examine the rate of BRAF mutation and the expression profiles of CK19, galectin-3, CD56, thyroid peroxidase (TPO) and Ki67 in papillary thyroid carcinoma (PTC) and papillary thyroid micro-carcinoma (PTMC). A total of 246 cases of thyroid disease were collected, including PTC, PTMC, nodular goiter (NG) and Hashimoto thyroiditis (HT). The results revealed that CK19 expression was 116/120 in PTC, 61/64 in PTMC, $2 / 34$ in NG and $1 / 28$ in HT. Galectin-3 positive expression was $115 / 120$ in PTC, 60/64 in PTMC, 6/34 in NG and 4/28 in HT. TPO positive expression was $8 / 120$ in PTC, $1 / 64$ in PTMC, 30/34 in NG and 25/28 in HT. CD56-positive expression was 12/120 in PTC, 3/64 in PTMC, 33/34 in NG and $26 / 28$ in HT. Ki67 labeling index was $2.52 \pm 0.46 \%$ in PTC (120 cases), $2.62 \pm 0.52 \%$ in PTMC (64 cases), $2.55 \pm 0.44 \%$ in $\mathrm{NG}$ (34 cases) and $2.58 \pm 0.48 \%$ in HT (28 cases). BRAF mutation rate was 93/120 in PTC, 47/64 in PTMC, 3/34 in NG and $2 / 28$ in HT. These results suggested that expression patterns of CK19, galectin-3, CD56 and TPO and BRAF mutation exhibit diagnosis value in thyroid disease. However, Ki67-positive rate exhibits no notable diagnosis value in thyroid disease.
\end{abstract}

\section{Introduction}

It is well-known that the incidence of papillary thyroid carcinoma (PTC) and papillary thyroid micro-carcinoma (PTMC) is increasing each year worldwide: An $~ 120.85 \%$ increase in

Correspondence to: Professor Lijiang Liu, Department of Pathology and Pathophysiology, School of Medicine, Jianghan University, 8 Sanjiaohu Road, Wuhan, Hubei 430056, P.R. China E-mail: liulijiang@163.com

*Contributed equally

Key words: papillary thyroid carcinoma, papillary thyroid micro-carcinoma, CK19, galectin-3, CD56, thyroid peroxidase, BRAF mutation
PTMC incidence and an $\sim 58.1 \%$ increase in PTC incidence was demonstrated between 1990-2015 (1-10). PTC and PTMC are the most common types of thyroid malignancies (11-21). However, distinguishing PTC and PTMC from thyroid papillary hyperplasia is challenging due to tumor heterogeneity (22-27). Occasionally, cases of papillary thyroid hyperplasia, in particular solitary nodules with papillary change, are difficult to distinguish from PTMC (22-27). Papillary formation is frequently observed in thyroid disease (benign or malignant), but the treatment plans differ considerably (1-5,7-10). In China, nodular goiter (NG) is a common disease; it was demonstrated that the incidence of NG was 5.0-10.0\% from 1990 to 2011, and it was 4 times higher in females compared with in males in 2011 (11-16). It can be difficult to distinguish papillary hyperplasia in PTMC from papillary hyperplasia nodules of NG (11-16). Therefore, it was proposed that the increasing incidence of PTC and PTMC may partly be due to misdiagnosis. Thus, in the present study, the diagnosis of cases in Wuhan Puai Hospital (Wuhan, China) and Jiangda Pathology Institute (Wuhan, China) was reviewed. The expression profiles of CK19, galectin-3, CD56 and thyroid peroxidase (TPO), as well as BRAF mutation, were used to distinguish between benign and malignant papillary formation. Although numerous previous studies have reported that CK19, galectin-3, CD56 and TPO expression, as well as BRAF mutation, are markers for PTC and PTMC diagnosis (17-49), few studies have considered them together and studied their value in the diagnosis of PTC and PTMC. In the present study, the diagnostic value of CK19, galectin-3, CD56, TPO and Ki67 expression and BRAF mutation in PTC and PTMC were investigated.

\section{Materials and methods}

Patients. A total of 246 thyroid samples from the Department of Pathology, Wuhan Puai Hospital (Wuhan, China) and the Department of Histopathology, Jiangda Pathology Institute, Jianghan University (Wuhan, China) obtained during biopsy between January 2010 and March 2016 were used in the present study. The samples included 120 cases of PTC (33 males, 87 females; mean age, 52.3 years; age range, 17-72 years), 64 cases of PTMC (22 males, 42 females; mean age, 50.7 years; age range, 21-69 years) and 62 non-malignant cases (18 males, 
44 females; mean age, 47.5 years; age range, $28-65$ years). The 62 non-malignant cases included 34 cases of NG and 28 cases of Hashimoto thyroiditis (HT). The diagnosis of PTC and PTMC was based on characteristic cytological features, including nuclear irregularity, nuclear groove and pseudoinclusions and psammoma bodies (Fig. 1A) (10), and immunohistochemistry results, including $\mathrm{CK} 19^{+}$and galectin $-3^{+}$, which was performed using the immunohistochemistry methods described below (28). All resected specimens were fixed in $10 \%$ neutral buffered formalin ( $\mathrm{pH}$ 7.4) at room temperature for $24 \mathrm{~h}$, embedded in paraffin, and cut into 4- $\mu \mathrm{m}$ sections. Informed consent was obtained from all patients, and all experiments were approved by the Ethics Committee of Jianghan University.

Reagents. Anti-CK19 (keratin 19) mouse monoclonal antibody (cat. no. TA500212), anti-TPO rabbit polyclonal antibody (cat. no. TA323628), rabbit polyclonal anti-Ki67 antibody (cat. no. TA314198), rabbit polyclonal anti-galectin-3 antibody anti-galectin-3 antibody (cat. no. AP54962SU-N), and mouse monoclonal anti-CD56 antibody (cat. no. TA353710) were purchased from OriGene Technologies, Inc. (Beijing, China). The biotin-streptavidin horseradish peroxidase detection systems (SP test kit; cat. no. SP-9000) and diaminobenzidine (DAB) colorization test kit (cat. no. ZLI-9017) were purchased from Beijing Zhongshan Golden Bridge Biotechnology, Co., Ltd. (Beijing, China). The TIANamp FFPE DNA kit (DP331) was purchased from Tiangen Biotech Co., Ltd. (Beijing, China). The Human BRAF V600E gene mutation detection kit was from Wuhan YZY Biopharma Co., Ltd. (Wuhan, China).

Histology and immunohistochemistry. Standard hematoxylin and eosin staining was performed on $4-\mu \mathrm{m}$ paraffin sections of above specimens: Tissues that were fixed in $10 \%$ neutral buffered formalin for $12 \mathrm{~h}$ at room temperature, the processed and embedded in paraffin wax. Sections measuring $4-\mu \mathrm{m}$ thickness were stained in $0.5 \%$ hematoxylin staining solution $(1 \mathrm{~g}$ haematoxylin, $15 \mathrm{~g}$ aluminum potassium sulfate, $10 \mathrm{ml}$ absolute ethyl alcohol and $200 \mathrm{ml}$ distilled water) for $10 \mathrm{~min}$ at room temperature. The slides were placed under running tap water at room temperature for at least $10 \mathrm{~min}$ following $1 \%$ hydrochloric acid alcohol differentiation for $1 \mathrm{~min}$ at room temperature. Then, the samples were stained in working $1 \%$ eosin Y staining solution $(1 \mathrm{~g}$ eosin $\mathrm{Y}, 100 \mathrm{ml}$ distilled water and 1 drop glacial acetic acid) for $1 \mathrm{~min}$ at room temperature and dehydrated at room temperature. Then, the slides were viewed with a microscope subsequent to the addition of a coverslip. Immunostaining was performed using following appropriate antibodies on $4-\mu \mathrm{m}$ tumor sections using a 'two-step' method. The tissue slides were deparaffinized twice with $100 \%$ xylene for $15 \mathrm{~min}$ at $37^{\circ} \mathrm{C}$ and rehydrated gradually in an ethanol series (100, 95 and $80 \%$ ethanol) for $10 \mathrm{~min}$ at room temperature. The endogenous peroxidase activity was inhibited by incubation for $10 \mathrm{~min}$ at room temperature in a $3 \%$ hydrogen peroxide/methanol buffer. Antigen retrieval was performed by immersing the slides in an ethylenediamine tetraacetic acid buffer $(\mathrm{pH}$ 8.0), followed by boiling in a water bath at $100^{\circ} \mathrm{C}$ for $10 \mathrm{~min}$. The slides were rinsed in PBS and subsequently incubated with anti-CK19 (keratin 19) mouse monoclonal antibody (dilution 1:100; cat. no. TA500212), rabbit polyclonal anti-galectin-3 antibody (dilution 1:100; cat. no. AP54962SU-N), anti-TPO rabbit polyclonal

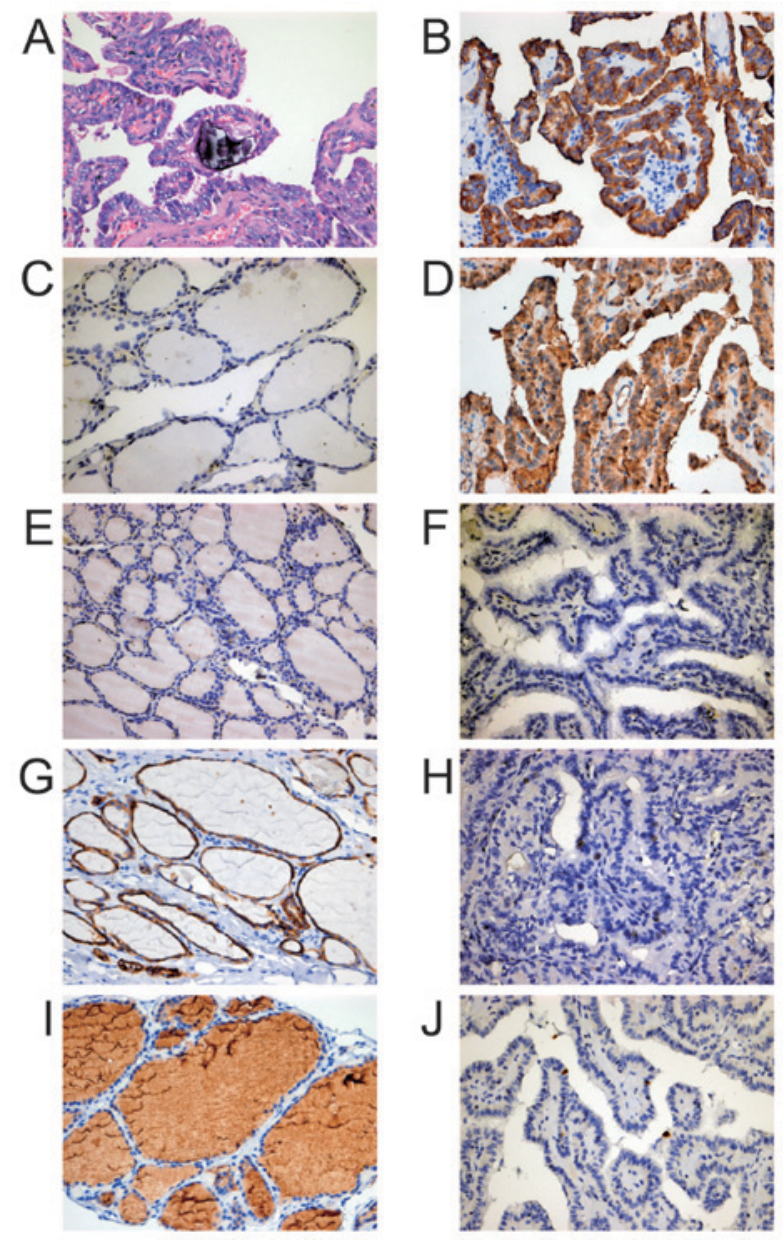

Figure 1. Immunohistochemical staining and histological morphology of thyroid samples. (A) Hematoxylin and eosin staining of PTC. Magnification, x400. (B) Representative staining for CK19 in PTC. (C) Negative expression of CK19 in NG. (D) Representative staining for galectin-3 in PTC. (E) Negative expression of galectin-3 in NG. (F) Negative expression of TPO in PTC. (G) Representative staining for TPO in NG. (H) Negative expression of CD56 in PTC. (I) Representative staining for CD56 in NG. (J) Representative staining for Ki67 in PTC. PTC, papillary thyroid carcinoma; NG, nodular goiter; TPO, thyroid peroxidase.

antibody (dilution 1:100; cat. no. TA323628), mouse monoclonal anti-CD56 antibody (dilution 1:100; cat. no. TA353710) or rabbit polyclonal anti-Ki67 antibody (dilution 1:100; cat. no. TA314198) (all from OriGene Technologies, Inc.) overnight at $4^{\circ} \mathrm{C}$ in a humidified chamber. Following this incubation, the slides were washed three times with PBS containing $0.05 \%$ Tween-20. The slides were then incubated with biotin-labeled goat anti-mouse/Rabbit IgG secondary antibodies antibody at a ready-to-use dilution (cat. no. SP-9000; Beijing Zhongshan Golden Bridge Biotechnology, Co., Ltd.) for $1 \mathrm{~h}$ at $37^{\circ} \mathrm{C}$. The slides were then washed three times and developed with DAB chromogen. The slides were then washed gently with tap water, prior to counterstaining with hematoxylin at room temperature for $10 \mathrm{~min}$, and then were observed by light microscope (magnification, x400, BX51; Olympus Corporation, Tokyo, Japan).

Evaluation of immunohistochemical staining. For staining of CK19, galectin-3, CD56 and TPO, the signals were considered positive when immunoreactivity was clearly observed in the cell membrane and/or cytoplasm by light microscope 
Table I. CK19 expression.

\begin{tabular}{|c|c|c|c|c|}
\hline \multirow[b]{2}{*}{ Groups } & \multicolumn{2}{|c|}{ CK19 expression } & \multirow[b]{2}{*}{$\chi^{2}$} & \multirow[b]{2}{*}{ P-value } \\
\hline & Positive & Negative & & \\
\hline PTC vs. NG & & & 116.8 & $\mathrm{P}<0.001$ \\
\hline PTC & 116 & 4 & & \\
\hline NG & 2 & 32 & & \\
\hline PTC vs. HT & & & 113.3 & $\mathrm{P}<0.001$ \\
\hline PTC & 116 & 4 & & \\
\hline HT & 1 & 27 & & \\
\hline PTC vs. PTMC & & & 0.028 & $\mathrm{P}=0.957$ \\
\hline PTC & 116 & 4 & & \\
\hline PTMC & 61 & 3 & & \\
\hline PTMC vs. NG & & & 77.5 & $\mathrm{P}<0.001$ \\
\hline PTMC & 61 & 3 & & \\
\hline NG & 2 & 32 & & \\
\hline PTMC vs. HT & & & 70.5 & $\mathrm{P}<0.001$ \\
\hline PTMC & 61 & 3 & & \\
\hline HT & 1 & 27 & & \\
\hline NG vs. HT & & & 0.298 & $\mathrm{P}=0.863$ \\
\hline NG & 2 & 32 & & \\
\hline HT & 1 & 27 & & \\
\hline
\end{tabular}

PTC, papillary thyroid carcinoma; PTMC, papillary thyroid micro-carcinoma; NG, nodular goiter; HT, Hashimoto thyroiditis.

(magnification, $x 400)$. It was scored manually, and all fields of view that included the tumor were examined. For each antibody, with the exception of Ki67, no staining or weak staining in $<10 \%$ of the cells was scored as negative, and staining in $\geq 10 \%$ of cells was scored as positive. The known positive or negative controls were taken at the same time; the judgement of the staining was compared with the control. If the staining was the same as the negative control or only no more than $10 \%$ cells were weakly stained, it was scored as negative. While, if the staining was the same as the positive control or $>10 \%$ cells were stained, it was scored as negative. The individual cells were counted. The proportion was the number of positive cells divided by the total number of cells. For Ki67 staining, the Ki67 staining in the cell nuclei was examined in 500 cells manually and indicated as a percentage of the total nuclei. All above experiments were scored or examined by at least two pathologists.

DNA isolation from formalin-fixed, paraffin-embedded (FFPE) tissue sections. DNA was isolated from 5-8 FFPE tissue sections from each patient using the TIANamp FFPE DNA kit, according to the manufacturer's instructions. The DNA was stored at $-20^{\circ} \mathrm{C}$.

BRAF mutation detection. BRAF mutation was detected using the Human BRAF V600E gene mutation detection kit (Wuhan YZY Biopharma Co., Ltd.) with TaqMan probe, according to the manufacturer's instructions. The all primers used were included as part of the Human BRAF V600E gene mutation detection kit (Wuhan YZY Biopharma Co., Ltd.). DNA amplification was performed with the StepOnePlus Real-Time PCR system (Thermo Fisher Scientific, Inc., Waltham, MA, USA) in a total volume of $25 \mu \mathrm{l}$. The thermocycling conditions were as follows: An initial UNG treatment for $10 \mathrm{~min}$ at $37^{\circ} \mathrm{C}$ and pre-degeneration for $5 \mathrm{~min}$ at $95^{\circ} \mathrm{C}$, then 40 cycles of denaturation at $95^{\circ} \mathrm{C}$ for $15 \mathrm{sec}$, an annealing step at $60^{\circ} \mathrm{C}$ for $60 \mathrm{sec}$. After the reaction, according to the amplification curve, suitable fluorescence thresholds (threshold defined in the amplification curve of logarithmic exponential growth) were identified and $\mathrm{Cq}$ values were calculated (29).

Statistical analysis. Statistical analysis was performed using SPSS 12.0 software (SPSS, Inc., Chicago, IL, USA). Data are presented as the mean \pm standard deviation. The $\chi^{2}$ test and Fisher's exact test were used to compare immunohistochemistry results between the experimental groups and the control groups. A one-way analysis of variance and Dunnett's test was used to compare Ki67 immunohistochemistry results between groups. $\mathrm{P}<0.05$ was considered to indicate a statistically significant difference. All experiments were performed at least three times.

\section{Results}

CK19 expression. CK19 staining was detected predominantly in the cytoplasm in PTC (Fig. 1B), but was absent in NG (Fig. 1C). Positive staining of CK19 was detected in 116/120 cases of PTC, 61/64 in PTMC, 2/34 in NG and $1 / 28$ in HT (Table I). CK19 expression was significantly 
Table II. Galectin-3 expression.

\begin{tabular}{|c|c|c|c|c|}
\hline \multirow[b]{2}{*}{ Groups } & \multicolumn{2}{|c|}{ Galectin-3 expression } & \multirow[b]{2}{*}{$\chi^{2}$} & \multirow[b]{2}{*}{ P-value } \\
\hline & Positive & Negative & & \\
\hline PTC vs. NG & & & 91.6 & $\mathrm{P}<0.001$ \\
\hline PTC & 115 & 5 & & \\
\hline NG & 6 & 28 & & \\
\hline PTC vs. HT & & & 90.7 & $\mathrm{P}<0.001$ \\
\hline PTC & 115 & 5 & & \\
\hline HT & 4 & 24 & & \\
\hline PTC vs. PTMC & & & 0.07 & $P>0.791$ \\
\hline PTC & 115 & 5 & & \\
\hline PTMC & 60 & 4 & & \\
\hline PTMC vs. NG & & & 55.1 & $\mathrm{P}<0.001$ \\
\hline PTMC & 60 & 4 & & \\
\hline $\mathrm{NG}$ & 6 & 28 & & \\
\hline PTMC vs. HT & & & 54.4 & $\mathrm{P}<0.001$ \\
\hline PTMC & 60 & 4 & & \\
\hline HT & 4 & 24 & & \\
\hline NG vs. HT & & & 0.13 & $P>0.72$ \\
\hline $\mathrm{NG}$ & 6 & 28 & & \\
\hline HT & 4 & 24 & & \\
\hline
\end{tabular}

PTC, papillary thyroid carcinoma; PTMC, papillary thyroid micro-carcinoma; NG, nodular goiter; HT, Hashimoto thyroiditis.

more common in PTC compared with NG $(\mathrm{P}<0.001)$, PTC compared with HT $(\mathrm{P}<0.001)$, PTMC compared with NG $(\mathrm{P}<0.001)$ and PTMC compared with HT $(\mathrm{P}<0.001$; Table I). However, no significant differences in CK19 expression were observed between PTC and PTMC, or between NG and HT (Table I).

Galectin-3 expression. Galectin-3 expression was detected predominantly in the cytoplasm and nucleus in PTC (Fig. 1D), but was absent in NG (Fig. 1E). Galectin-3-positive staining was detected in 115/120 cases of PTC, 60/64 of PTMC, 6/34 of NG and 4/28 of HT. Galectin-3 expression was significantly more common in PTC compared with NG $(\mathrm{P}<0.001)$, PTC compared with HT $(\mathrm{P}<0.001)$, PTMC compared with NG $(\mathrm{P}<0.001)$ and PTMC compared with HT $(\mathrm{P}<0.001$; Table II). No significant differences in galectin-3 expression were observed between PTC and PTMC, or between NG and HT (Table II).

TPO expression. TPO expression was detected predominantly in the plasma membrane in PTC (Fig. 1F), but was absent in NG (Fig. 1G). TPO-positive staining was detected in 8/120 cases of PTC, 1/64 in PTMC, 30/34 in NG and 25/28 in HT. TPO expression was significantly less common in PTC compared with NG ( $\mathrm{P}<0.001)$, PTC compared with HT $(\mathrm{P}<0.001)$, PTMC compared with NG $(\mathrm{P}<0.001)$ and PTMC compared with HT $(\mathrm{P}<0.001$; Table III). However, no significant differences were observed between PTC and PTMC, or between NG and HT (Table III).
CD56 expression. CD56 expression was detected predominantly in the cytoplasm in PTC (Fig. 1H), but was absent in NG (Fig. 1I). CD56 positive staining was detected in 12/120 cases of PTC, 3/64 in PTMC, 33/34 in NG and 26/28 in HT. CD56 expression level was significantly less common in PTC compared with NG $(\mathrm{P}<0.001)$, PTC compared with HT $(\mathrm{P}<0.001)$, PTMC compared with NG $(\mathrm{P}<0.001)$ and PTMC compared with HT $(\mathrm{P}<0.001$; Table IV). No significant differences in CD56 expression were observed between PTC and PTMC, or between NG and HT (Table IV).

Ki67 expression. Ki67 expression was detected predominantly in the cell nucleus (Fig. 1J). Ki67-positive index was $2.52 \pm 0.46 \%$ in PTC (120 cases), $2.62 \pm 0.52 \%$ in PTMC (64 cases), $2.55 \pm 0.44 \%$ in NG (34 cases) and $2.58 \pm 0.48 \%$ in HT (28 cases). Ki67-positive index was not significantly different between PTC and NG, PTC and HT, PTC and PTMC, PTMC and NG, PTMC and HT or NG and HT (Table V).

$B R A F$ mutation rate. The BRAF mutation rate was identified to be $77.5 \%(93 / 120)$ in PTC, $73.4 \%$ (47/64) in PTMC, $8.8 \%(3 / 34)$ in NG and $7.1 \%(2 / 28)$ in HT. The BRAF mutation rate was significantly higher in PTC compared with NG $(\mathrm{P}<0.001)$, PTC compared with HT $(\mathrm{P}<0.001)$, PTMC compared with NG $(\mathrm{P}<0.001)$ and PTMC compared with HT $(\mathrm{P}<0.001$; Table VI). However, no significant differences in BRAF mutation rate were observed between PTC and PTMC, or between NG and HT (Table VI). 
Table III. TPO expression.

\begin{tabular}{|c|c|c|c|c|}
\hline \multirow[b]{2}{*}{ Groups } & \multicolumn{2}{|c|}{ TPO expression } & \multirow[b]{2}{*}{$\chi^{2}$} & \multirow[b]{2}{*}{ P-value } \\
\hline & Positive & Negative & & \\
\hline PTC vs. NG & & & 90.5 & $\mathrm{P}<0.001$ \\
\hline PTC & 8 & 112 & & \\
\hline NG & 30 & 4 & & \\
\hline PTC vs. HT & & & 84.7 & $\mathrm{P}<0.001$ \\
\hline PTC & 8 & 112 & & \\
\hline $\mathrm{HT}$ & 25 & 3 & & \\
\hline PTC vs. PTMC & & & 1.36 & $\mathrm{P}>0.242$ \\
\hline PTC & 8 & 112 & & \\
\hline PTMC & 1 & 63 & & \\
\hline PTMC vs. NG & & & 73.2 & $\mathrm{P}<0.001$ \\
\hline PTMC & 1 & 63 & & \\
\hline NG & 30 & 4 & & \\
\hline PTMC vs. HT & & & 69.7 & $\mathrm{P}<0.001$ \\
\hline PTMC & 1 & 63 & & \\
\hline $\mathrm{HT}$ & 25 & 3 & & \\
\hline NG vs. HT & & & 0.07 & $\mathrm{P}>0.785$ \\
\hline NG & 30 & 4 & & \\
\hline HT & 25 & 3 & & \\
\hline
\end{tabular}

PTC, papillary thyroid carcinoma; PTMC, papillary thyroid micro-carcinoma; NG, nodular goiter; HT, Hashimoto thyroiditis; TPO, thyroid peroxidase.

Table IV. CD56 expression.

\begin{tabular}{|c|c|c|c|c|}
\hline \multirow[b]{2}{*}{ Groups } & \multicolumn{2}{|c|}{ CD56 expression } & \multirow[b]{2}{*}{$\chi^{2}$} & \multirow[b]{2}{*}{ P-value } \\
\hline & Positive & Negative & & \\
\hline PTC vs. NG & & & 92.9 & $\mathrm{P}<0.001$ \\
\hline PTC & 12 & 108 & & \\
\hline NG & 33 & 1 & & \\
\hline PTC vs. HT & & & 77.3 & $\mathrm{P}<0.001$ \\
\hline PTC & 12 & 108 & & \\
\hline HT & 26 & 2 & & \\
\hline PTC vs. PTMC & & & 0.97 & $\mathrm{P}>0.331$ \\
\hline PTC & 12 & 108 & & \\
\hline PTMC & 3 & 61 & & \\
\hline PTMC vs. NG & & & 77.6 & $\mathrm{P}<0.001$ \\
\hline PTMC & 3 & 61 & & \\
\hline NG & 33 & 1 & & \\
\hline PTMC vs. HT & & & 66.1 & $\mathrm{P}<0.001$ \\
\hline PTMC & 3 & 61 & & \\
\hline HT & 26 & 2 & & \\
\hline NG vs. HT & & & 0.03 & $\mathrm{P}>0.863$ \\
\hline NG & 33 & 1 & & \\
\hline HT & 26 & 2 & & \\
\hline
\end{tabular}

PTC, papillary thyroid carcinoma; PTMC, papillary thyroid micro-carcinoma; NG, nodular goiter; HT, Hashimoto thyroiditis. 
Table V. Ki67 expression.

\begin{tabular}{lllll}
\hline & \multicolumn{2}{c}{ Ki67, \% } & & F-value \\
\cline { 2 - 4 } Groups & Mean & SD & 0.521 & \\
\hline PTC & 2.52 & 0.46 & & \\
PTMC & 2.62 & 0.52 & 0.669 \\
NG & 2.55 & 0.44 & \\
HT & 2.58 & 0.48 & \\
\hline
\end{tabular}

PTC, papillary thyroid carcinoma; PTMC, papillary thyroid micro-carcinoma; NG, nodular goiter; HT, Hashimoto thyroiditis; SD, standard deviation.

Table VI. Mutation rate of BRAF.

\begin{tabular}{|c|c|c|c|c|}
\hline \multirow[b]{2}{*}{ Groups } & \multicolumn{2}{|c|}{ BRAF } & \multirow[b]{2}{*}{$\chi^{2}$} & \multirow[b]{2}{*}{ P-value } \\
\hline & Mutation & No mutation & & \\
\hline PTC vs. NG & & & 50.3 & $\mathrm{P}<0.001$ \\
\hline PTC & 93 & 27 & & \\
\hline NG & 3 & 31 & & \\
\hline PTC vs. HT & & & 48.9 & $\mathrm{P}<0.001$ \\
\hline PTC & 93 & 27 & & \\
\hline HT & 2 & 26 & & \\
\hline PTC vs. PTMC & & & 0.19 & $P>0.664$ \\
\hline PTC & 93 & 27 & & \\
\hline PTMC & 47 & 17 & & \\
\hline PTMC vs. NG & & & 34.5 & $\mathrm{P}<0.001$ \\
\hline PTMC & 47 & 17 & & \\
\hline NG & 3 & 31 & & \\
\hline PTMC vs. HT & & & 31.7 & $\mathrm{P}<0.001$ \\
\hline PTMC & 47 & 17 & & \\
\hline HT & 2 & 26 & & \\
\hline NG vs. HT & & & 0.05 & $\mathrm{P}>0.821$ \\
\hline NG & 3 & 31 & & \\
\hline HT & 2 & 26 & & \\
\hline
\end{tabular}

PTC, papillary thyroid carcinoma; PTMC, papillary thyroid micro-carcinoma; NG, nodular goiter; HT, Hashimoto thyroiditis.

\section{Discussion}

Papillary formation is often observed in benign and malignant thyroid diseases (30-32), meaning that it is difficult to distinguish between benign and malignant lesions (30-32). The pathological morphological characteristics, such as papillary architecture with typically complex branching, nuclear features including nuclear irregularity, nuclear groove and pseudoinclusion and psammoma bodies, are widely used in the diagnosis of thyroid diseases. However, to distinguish PTC from thyroid papillary hyperplasia and solitary nodules with papillary change is challenging due to tumor heterogeneity. Thus, immunohistochemistry is also essential in the diagnosis (30-32).
CK19 is a member of the keratin family that is an intermediate filament protein in epithelial cells (33). CK19 is highly expressed in papillary carcinoma, but not in benign follicular nodules, which is useful in diagnosis (33). In previous studies, the CK19 positive rate was reported to be $84-100 \%$ in PTC, $59-84 \%$ in PTMC, $26.80 \%$ in NG and $20 \%$ in HT (33-38). In the present study, CK19 expression was detected in 96.7\% (116/120) of PTC, 95.3\% (61/64) of PTMC, 5.9\% (2/34) of NG and $3.6 \%(1 / 28)$ of HT. Thus, CK19 expression is indicated to be valuable in the diagnosis of thyroid carcinoma.

Galectin-3 is a member of the $\beta$-galactoside-binding mammalian family of lectins that serves functions in metastasis, angiogenesis, proliferation and apoptosis of multiple tumor types, including thyroid carcinoma (39). In previous 
studies, the galectin-3 expression rate was reported to be 64.86-100\% in PTC, 45.7-98\% in PTMC, $0-52.6 \%$ in NG and $19-38.9 \%$ in HT $(33,38,40-45)$. In the present study, galectin-3 positive rate was $95.8 \%(115 / 120)$ in PTC, 93.8\% (60/64) of PTMC, $17.6 \%(6 / 34)$ of NG and $14.3 \%$ (4/28) in HT. Thus, galectin-3 has the potential to be used as a diagnostic marker for thyroid cancer.

TPO is a membrane-bound protein essential for the production of thyroid hormones. It catalyzes the iodination and coupling of tyrosyl residues to thyroglobulin to form thyroid hormones T3 and T4 (46). TPO expression is used as a thyroid differentiation marker (46) and is decreased in thyroid carcinoma (46). In previous studies, TPO expression rate was reported to be $3-29.4 \%$ in PTC, 9.4\% in PTMC and $100 \%$ in benign thyroid disease $(34,46-48)$. In the present study, TPO expression was $6.7 \%(8 / 120)$ in PTC, $1.6 \%$ (1/64) in PTMC, $88.2 \%(30 / 34)$ in NG and 89.3\% (25/28) in HT. These results indicated that the downregulation of TPO expression may be used for diagnosis of thyroid carcinoma.

CD56 is a member of the immunoglobulin superfamily that has five extracellular immunoglobulin domains and two fibronectin type III domains $(44,45,49,50)$. CD56 is expressed in thyroid follicular cells (43). Downregulation or lack of CD56 expression is often observed in PTC, thyroid follicular carcinoma and thyroid anaplastic carcinoma (49). In previous studies, CD56 expression rate was reported to be $0-24.3 \%$ in PTC, $0-60 \%$ in PTMC and $91.7-100 \%$ in benign thyroid diseases $(43,45,49,50)$. In the present study, CD56 expression was $10 \%(12 / 120)$ in PTC, $4.7 \%$ (3/64) in PTMC, $97.1 \%(33 / 34)$ in NG and $92.8 \%(26 / 28)$ in HT. These results indicated that the downregulation of CD56 has value in the diagnosis of thyroid tumors.

Ki67 is a widely used marker of cell proliferation and is used for differential diagnosis between malignant and benign human neoplasms (32). However, no significant difference in Ki67 labeling index was observed between malignant and benign thyroid neoplasms in a previous study (32). Ki67 labeling index was previously reported to be $0-20 \%$ in PTC, $0-20 \%$ in PTMC and 0-1\% in benign thyroid disease (37,51-53). It was proposed that $\mathrm{Ki} 67$ may be used as a marker for cell proliferation and prognosis in PTC (54). However, in the present study, Ki67 labeling index was $2.52 \pm 0.46 \%$ in PTC (120 cases), $2.62 \pm 0.52 \%$ in PTMC (64 cases), $2.55 \pm 0.44 \%$ in NG (34 cases) and $2.58 \pm 0.48 \%$ in HT (28 cases). Thus, Ki67 labeling index has little value in the diagnosis of malignant and benign thyroid neoplasms. This is likely to be due the fact that PTC and PTMC are low proliferation tumors (37,51-53).

BRAF belongs to the family of RAF proteins and is an intracellular effector of the mitogen-activated protein kinase-signaling cascade (55). The BRAF V600E mutation is a molecular marker that has been reported in thyroid carcinoma (56-64). BRAF mutation rate was previously reported to be $29-83 \%$ in PTC, 37.5-77\% in PTMC and 0.2-5.7\% in benign thyroid disease $(19,33-35,65-68)$. In the present study, BRAF mutation rate was $77.5 \%(93 / 120)$ in PTC, $73.4 \%$ (47/64) in PTMC, $8.8 \%$ (3/34) in NG and 7.1\% (2/28) in HT. In addition, the present results suggested that BRAF mutation was associated with the expression of CK19 and galectin-3 in PTC and PTMC. These results suggested that BRAF mutation may be valuable in the diagnosis of thyroid carcinoma.
The incidence of NG is high in China compared with papillary formation (11-16). However, it can be difficult to distinguish NG from malignant papillary formation (11-16). The present study presents evidence to support the view that analysis of expression patterns of CK19, galectin-3, TPO and CD56, together with BRAF mutation, will be useful in the diagnosis of thyroid carcinoma. It was demonstrated that CK19 and galectin-3 were often positively expressed, and TPO and CD56 were often negatively expressed, in PTC and PTMC, and it was revealed that the BRAF mutation rate was high in PTC and PTMC. However, not all PTC and PTMC cases indicated that CK19 and galectin-3 were completely positively expressed. Therefore, these negative cases require additional analysis.

\section{Acknowledgements}

The present study was supported by the National Natural Science Foundation of China (grant nos. 81470110, 81272754 and 30870981) and the Science Foundation of Health Office of Hubei Province (grant no. WJ2015Z059). The authors would like to thank Professor Zhaoyi Wang for providing critical reading of this study.

\section{References}

1. Ito $Y$, Nikiforov YE, Schlumberger $M$ and Vigneri R: Increasing incidence of thyroid cancer: Controversies explored. Nat Rev Endocrinol 9: 178-184, 2013.

2. Jung KW, Won YJ, Kong HJ, Oh CM, Seo HG and Lee JS: Cancer statistics in Korea: Incidence, mortality, survival and prevalence in 2010. Cancer Res Treat 45: 1-14, 2013.

3. Ito Y, Fukushima M, Higashiyama T, Kihara M, Takamura Y, Kobayashi K, Miya A and Miyauchi A: Incidence and predictors of right paraesophageal lymph node metastasis of N0 papillary thyroid carcinoma located in the right lobe. Endocr J 60: 389-392, 2013.

4. Joshi P, Nair S, Nair D and Chaturvedi P: Incidence of occult papillary carcinoma of thyroid in Indian population: Case series and review of literature. J Cancer Res Ther 10: 693-695, 2014.

5. Wang J, Gao L, Song C and Xie L: Incidence of metastases from 524 patients with papillary thyroid carcinoma in cervical lymph nodes posterior to the sternoclavicular joint (level VIa): Relevance for endoscopic thyroidectomy. Surgery 159: 1557-1564, 2016.

6. Zhu J, Wang X, Zhang X, Li P and Hou H: Clinicopathological features of recurrent papillary thyroid cancer. Diagn Pathol 10: 96, 2015.

7. Liu X, Ouyang D, Li H, Zhang R, Lv Y, Yang A and Xie C: Papillary thyroid cancer: Dual-energy spectral CT quantitative parameters for preoperative diagnosis of metastasis to the cervical lymph nodes. Radiology 275: 167-176, 2015.

8. Zhang YZ, Qin F, Han ZG, Liu Q, Zhou L and Wang YW: Prognostic significance of DLL4 expression in papillary thyroid cancer. Eur Rev Med Pharmacol Sci 19: 2901-2905, 2015.

9. Zhou SF, Hu SY, Ma L, Miao L and Mao WZ: Correlations between papillary thyroid cancer and peripheral blood levels of matrix metalloproteinase-2, matrix metalloproteinase-9, tissue inhibitor of metalloproteinase-1, and tissue inhibitor of metalloproteinase-2. Chin Med J (Engl) 126: 1925-1929, 2013.

10. Zhu Y, Wang C, Zhang GN, Shi Y, Xu SQ, Jia SJ and He R: Papillary thyroid cancer located in malignant struma ovarii with omentum metastasis: A case report and review of the literature. World J Surg Oncol 14: 17, 2016.

11. Shi RL, Qu N, Liao T, Wang YL, Wang Y, Sun GH and Ji QH: Expression, clinical significance and mechanism of Slit2 in papillary thyroid cancer. Int J Oncol 48: 2055-2062, 2016.

12. Shi RL, Qu N, Liao T, Wei WJ, Lu ZW, Ma B, Wang YL and Ji QH: Relationship of body mass index with BRAF (V600E) mutation in papillary thyroid cancer. Tumour Biol 37: 8383-8390, 2016. 
13. Shi X, Liu R, Basolo F, Giannini R, Shen X, Teng D, Guan H, Shan Z, Teng W, Musholt TJ, et al: Differential clinicopathological risk and prognosis of major papillary thyroid cancer variants. J Clin Endocrinol Metab 101: 264-274, 2016.

14. Su X, Li Z, He C, Chen W, Fu X and Yang A: Radiation exposure, young age, and female gender are associated with high prevalence of RET/PTC1 and RET/PTC3 in papillary thyroid cancer: A meta-analysis. Oncotarget 7: 16716-16730, 2016.

15. Gao B, Tian W, Jiang Y, Zhang X, Zhao J, Zhang S, Chen J and Luo D: Peri-operative treatment of giant nodular goiter. Int J Med Sci 9: 778-785, 2012.

16. Tan Z, Ge MH, Zheng CM, Wang QL, Nie XL and Jiang LH: The significance of Delphian lymph node in papillary thyroid cancer. Asia Pac J Clin Oncol 13: e389-e393, 2017.

17. Ma YJ, Deng XL and Li HQ: BRAF $\left(V^{600} E\right)$ mutation and its association with clinicopathological features of papillary thyroid microcarcinoma: A meta-analysis. J Huazhong Univ Sci Technolog Med Sci 35: 591-599, 2015

18. Lu ZZ, Zhang Y, Wei SF, Li DS, Zhu QH, Sun SJ, Li M and Li LI: Outcome of papillary thyroid microcarcinoma: Study of 1,990 cases. Mol Clin Oncol 3: 672-676, 2015.

19. Qu N, Zhang L, Ji QH, Chen JY, Zhu YX, Cao YM and Shen Q: Risk factors for central compartment lymph node metastasis in papillary thyroid microcarcinoma: A meta-analysis. World J Surg 39: 2459-2470, 2015.

20. Zhang LY, Liu ZW, Liu YW, Gao WS and Zheng CJ: Risk factors for nodal metastasis in $\mathrm{cNO}$ papillary thyroid microcarcinoma Asian Pac J Cancer Prev 16: 3361-3363, 2015

21. Zhang L, Liu Z, Liu Y, Gao W and Zheng C: The clinical prognosis of patients with $\mathrm{cN} 0$ papillary thyroid microcarcinoma by central neck dissection. World J Surg Oncol 13: 138, 2015.

22. Park YJ, Kim YA, Lee YJ, Kim SH, Park SY, Kim KW, Chung JK Youn YK, Kim KH, Park DJ and Cho BY: Papillary microcarcinoma in comparison with larger papillary thyroid carcinoma in $\mathrm{BRAF}(\mathrm{V} 600 \mathrm{E})$ mutation, clinicopathological features, and immunohistochemical findings. Head Neck 32: 38-45, 2010.

23. Arora N, Turbendian HK, Kato MA, Moo TA, Zarnegar R and Fahey TJ III: Papillary thyroid carcinoma and microcarcinoma: Is there a need to distinguish the two? Thyroid 19: 473-477, 2009.

24. Batistatou A, Charalabopoulos K, Nakanishi Y, Vagianos C, Hirohashi S, Agnantis NJ and Scopa CD: Differential expression of dysadherin in papillary thyroid carcinoma and microcarcinoma: Correlation with E-cadherin. Endocr Pathol 19: 197-202, 2008

25. Antonaci A, Consorti F, Mardente S, Natalizi S, Giovannone G and Della Rocca C: Survivin and cyclin D1 are jointly expressed in thyroid papillary carcinoma and microcarcinoma. Oncol Rep 20: 63-67, 2008.

26. Kandogan T, Erkan N and Vardar E: Papillary carcinoma arising in a thyroglossal duct cyst with associated microcarcinoma of the thyroid and without cervical lymph node metastasis: A case report. J Med Case Rep 2: 42, 2008.

27. Barbaro D, Simi U, Meucci G, Lapi P, Orsini P and Pasquini C: Thyroid papillary cancers: Microcarcinoma and carcinoma, incidental cancers and non-incidental cancers-are they different diseases? Clin Endocrinol (Oxf) 63: 577-581, 2005.

28. Schneider DF and Chen $\mathrm{H}$ : New developments in the diagnosis and treatment of thyroid cancer. CA Cancer J Clin 63: 374-394, 2013.

29. Livak KJ and Schmittgen TD: Analysis of relative gene expression data using real-time quantitative PCR and the 2(-Delta Delta C(T)) method. Methods 25: 402-408, 2001

30. Romero-Rojas A, Cuervo-Martínez J, Osorio-Arango K and Olaya N: Histological variants and prognostic factors of papillary thyroid carcinoma at the Colombian Instituto Nacional de Cancerologia, 2006-2012. Biomedica 35: 429-436, 2015.

31. Sak SD: Variants of papillary thyroid carcinoma: Multiple faces of a familiar tumor. Turk Patoloji Derg 31 (Suppl 1): S34-S47, 2015.

32. Lee JH, Shin JH, Lee HW, Oh YL, Hahn SY and Ko EY: Sonographic and cytopathologic correlation of papillary thyroid carcinoma variants. J Ultrasound Med 34: 1-15, 2015.

33. Song Q, Wang D, Lou Y, Li C, Fang C, He X and Li J: Diagnostic significance of CK19, TG, Ki67 and galectin-3 expression for papillary thyroid carcinoma in the northeastern region of China. Diagn Pathol 6: 126, 2011.

34. Gong L, Chen P, Liu X, Han Y, Zhou Y, Zhang W, Li H, Li C and Xie J: Expressions of D2-40, CK19, galectin-3, VEGF and EGFR in papillary thyroid carcinoma. Gland Surg 1: 25-32, 2012.

35. Liu Z, Yu P, Xiong Y, Zeng W, Li X, Maiaiti Y, Wang S, Song H, Shi L, Liu C, et al: Significance of CK19, TPO, and HBME-1 expression for diagnosis of papillary thyroid carcinoma. Int J Clin Exp Med 8: 4369-4374, 2015.
36. Laco J, Ryska A, Cap J and Celakovský P: Expression of galectin-3, cytokeratin 19, neural cell adhesion molecule and E-cadhedrin in certain variants of papillary thyroid carcinoma. Cesk Patol 44: 103-107, 2008

37. Nasr MR, Mukhopadhyay S, Zhang S and Katzenstein AL: Absence of the BRAF mutation in $\mathrm{HBME}^{+}$and $\mathrm{CK} 19^{+}$atypical cell clusters in Hashimoto thyroiditis: Supportive evidence against preneoplastic change. Am J Clin Pathol 132: 906-912, 2009.

38. Lamba Saini M, Weynand B, Rahier J, Mourad M, Hamoir M and Marbaix E: Cyclin D1 in well differentiated thyroid tumour of uncertain malignant potential. Diagn Pathol 10: 32, 2015.

39. de Oliveira JT, Ribeiro C, Barros R, Gomes C, de Matos AJ, Reis CA, Rutteman GR and Gärtner F: Hypoxia up-regulates galectin-3 in mammary tumor progression and metastasis. PloS One 10: e0134458, 2015

40. Ma H, Yan J, Zhang C, Qin S, Qin L, Liu L, Wang X and Li N: Expression of papillary thyroid carcinoma-associated molecular markers and their significance in follicular epithelial dysplasia with papillary thyroid carcinoma-like nuclear alterations in Hashimoto's thyroiditis. Int J Clin Exp Pathol 7: 7999-8007, 2014.

41. Tang W, Huang C, Tang C, Xu J and Wang H: Galectin-3 may serve as a potential marker for diagnosis and prognosis in papillary thyroid carcinoma: A meta-analysis. OncoTargets Ther 9: 455-460, 2016

42. Gweon HM, Kim JA, Youk JH, Hong SW, Lim BJ, Yoon SO, Park YM and Son EJ: Can galectin-3 be a useful marker for conventional papillary thyroid microcarcinoma? Diagn Cytopathol 44: 103-107, 2016.

43. Londero SC, Godballe C, Krogdahl A, Bastholt L, Specht L, Sørensen CH, Pedersen HB, Pedersen U and Christiansen P: Papillary microcarcinoma of the thyroid gland: Is the immunohistochemical expression of cyclin D1 or galectin-3 in primary tumour an indicator of metastatic disease? Acta Oncol 47: 451-457, 2008

44. Dunđerović D, Lipkovski JM, Boričic I, Soldatović I, Božic V, Cvejić D and Tatić S: Defining the value of CD56, CK19, galectin 3 and HBME-1 in diagnosis of follicular cell derived lesions of thyroid with systematic review of literature. Diagn Pathol 10: 196, 2015.

45. Tong J, Wang Y and Da JP: Usefulness of CK19, HBME-1 and galectin-3 expressions in differential diagnosis of thyroid papillary microcarcinoma from benign lesions. Zhonghua Zhong Liu Za Zhi 33: 599-604, 2011 (In Chinese).

46. Caballero Y, López-Tomassetti EM, Favre J, Santana JR, Cabrera JJ and Hernández JR: The value of thyroperoxidase as a prognostic factor for differentiated thyroid cancer-a long-term follow-up study. Thyroid Res 8: 12, 2015.

47. Liu Z, Li X, Shi L, Maimaiti Y, Chen T, Li Z, Wang S, Xiong Y, Guo H, He W, et al: Cytokeratin 19, thyroperoxidase, HBME-1 and galectin-3 in evaluation of aggressive behavior of papillary thyroid carcinoma. Int J Clin Exp Med 7: 2304-2308, 2014.

48. Yang QX, Shao CK, Feng ZY, Huang BQ, Han AJ, Xiong M, Zhao WL and Wu TT: Detection of cytokeratin 19 and thyroperoxidase expressions in the diagnosis of thyroid diseases. Di Yi Jun Yi Da Xue Xue Bao 25: 678-681, 2005 (In Chinese).

49. Bizzarro T, Martini M, Marrocco C, D'Amato D, Traini E, Lombardi CP, Pontecorvi A, Fadda G, Larocca LM and Rossi ED: The role of CD56 in thyroid fine needle aspiration cytology: A pilot study performed on liquid based cytology. PloS One 10: e0132939, 2015

50. Scarpino S, Di Napoli A, Melotti F, Talerico C, Cancrini A and Ruco L: Papillary carcinoma of the thyroid: Low expression of NCAM (CD56) is associated with downregulation of VEGF-D production by tumour cells. J Pathol 212: 411-419, 2007.

51. Zhou Y, Jiang HG, Lu N, Lu BH and Chen ZH: Expression of ki67 in papillary thyroid microcarcinoma and its clinical significance. Asian Pac J Cancer Prev 16: 1605-1608, 2015.

52. Lubitz CC, Economopoulos KP, Pawlak AC, Lynch K, Dias-Santagata D, Faquin WC and Sadow PM: Hobnail variant of papillary thyroid carcinoma: An institutional case series and molecular profile. Thyroid 24: 958-965, 2014.

53. Clinckspoor I, Hauben E, Verlinden L, Van den Bruel A, Vanwalleghem L, Vander Poorten V, Delaere P, Mathieu C, Verstuyf A and Decallonne B: Altered expression of key players in vitamin $\mathrm{D}$ metabolism and signaling in malignant and benign thyroid tumors. J Histochem Cytochem 60: 502-511, 2012.

54. Huang Y, Dong W, Li J, Zhang H, Shan Z and Teng W: Differential expression patterns and clinical significance of estrogen receptor- $\alpha$ and $\beta$ in papillary thyroid carcinoma. BMC Cancer 14: 383, 2014. 
55. Rossi M, Buratto M, Tagliati F, Rossi R, Lupo S, Trasforini G, Lanza G, Franceschetti P, Bruni S, Degli Uberti E and Zatelli MC: Relevance of BRAF(V600E) mutation testing versus RAS point mutations and RET/PTC rearrangements evaluation in the diagnosis of thyroid cancer. Thyroid 25: 221-228, 2015

56. Koochak A, Rakhshani N, Karbalaie Niya MH, Tameshkel FS, Sohrabi MR, Babaee MR, Rezvani H, Bahar B, Imanzade F, Zamani F, et al: Mutation analysis of KRAS and BRAF genes in metastatic colorectal cancer: A first large scale study from Iran. Asian Pac J Cancer Prev 17: 603-608, 2016.

57. Gertz RJ, Nikiforov Y, Rehrauer W, McDaniel L and Lloyd RV: Mutation in BRAF and other members of the MAPK pathway in papillary thyroid carcinoma in the pediatric population. Arch Pathol Lab Med 140: 134-139, 2016.

58. Kowalska A, Walczyk A, Kowalik A, Pałyga I, Trybek T, Kopczyński J, Kajor M, Chrapek M, Pięciak L, Chłopek M, et al: Increase in papillary thyroid cancer incidence is accompanied by changes in the frequency of the BRAF V600E mutation: A single-institution study. Thyroid 26: 543-551, 2016.

59. Sun Y, Shi C, Shi T, Yu J and Li Z: Correlation between the $\mathrm{BRAF}(\mathrm{v} 600 \mathrm{E})$ gene mutation and factors influencing the prognosis of papillary thyroid microcarcinoma. Int J Clin Exp Med 8: 22525-22528, 2015.

60. Li J, Zhang S, Zheng S, Zhang D and Qiu X: The BRAF V600E mutation predicts poor survival outcome in patients with papillary thyroid carcinoma: A meta analysis. Int J Clin Exp Med 8: 22246-22253, 2015

61. Fu QF, Pan PT, Zhou L, Liu XL, Guo F, Wang L and Sun H: Clinical significance of preoperative detection of serum p53 antibodies and BRAF(V600E) mutation in patients with papillary thyroid carcinoma. Int J Clin Exp Med 8: 21327-21334, 2015.

62. Kowalska A, Kowalik A, Pałyga I, Walczyk A, Gąsior-Perczak D, Kopczyński J, Lizis-Kolus K, Szyska-Skrobot D, Hurej S, Radowicz-Chil A, et al: The usefulness of determining the presence of BRAF V600E mutation in fine-needle aspiration cytology in indeterminate cytological results. Endokrynol Pol 67: 41-47, 2016.
63. Beiša A, Beiša $V$, Stoškus M, Ostanevičiūtè E, Griškevičius L and Strupas K: The value of the repeated examination of BRAF V600E mutation status in diagnostics of papillary thyroid cancer. Endokrynol Pol 67: 35-40, 2016.

64. Tan J: Perianal melanoma with a BRAF gene mutation in a young Portuguese Roma native. BMJ Case Rep 2016: bcr2015212772, 2016.

65. Zou M, Baitei EY, Alzahrani AS, BinHumaid FS, Alkhafaji D, Al-Rijjal RA, Meyer BF and Shi Y: Concomitant RAS, RET/PTC, or BRAF mutations in advanced stage of papillary thyroid carcinoma. Thyroid 24: 1256-1266, 2014.

66. Henderson YC, Shellenberger TD, Williams MD, El-Naggar AK, Fredrick MJ, Cieply KM and Clayman GL: High rate of BRAF and RET/PTC dual mutations associated with recurrent papillary thyroid carcinoma. Clin Cancer Res 15: 485-491, 2009.

67. Li F, Chen G, Sheng C, Gusdon AM, Huang Y, Lv Z, Xu H, Xing $\mathrm{M}$ and Qu S: BRAFV600E mutation in papillary thyroid microcarcinoma: A meta-analysis. Endocr Relat Cancer 22: 159-168, 2015.

68. Syrenicz A, Koziołek M, Ciechanowicz A, Sieradzka A, Bińczak-Kuleta A and Parczewski M: New insights into the diagnosis of nodular goiter. Thyroid Res 7: 6, 2014.

This work is licensed under a Creative Commons Attribution-NonCommercial-NoDerivatives 4.0 International (CC BY-NC-ND 4.0) License. 